\title{
Informes
}

\section{Situación de la salud en Caldas}

Luz Maria González Robledo

Odontóloga U. Autónoma Jacqueline Vargas Charry

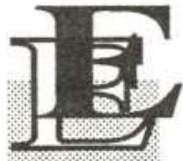

1 concepto de Salud, ha sido ampliamente discutido por muchos autores a través del tiempo. Es así como dentro de los modeániora los y diversas explicaciones que han surgido con el fin de describir los múltiples componentes que podrían influir en el proceso de salud-enfermedad, se encuentran valiosos aportes como los de Leavel y Clark, Lalonde y Blum, el concepto de «Campo de Salud» formulado por Laframboise (1974) y David Bersh, en donde unos y otros establecen el proceso de salud-enfermedad como un proceso multicausal.

Para efectos del análisis de la situación de salud de Caldas, diferenciaremos cuatro vectores a saber:

1. Biología Humana: Incluye los elementos que se desarrollan dentro del cuerpo humano como la herencia, los procesos de maduración, envejecimiento y funcionamiento de órganos y sistemas corporales. Este elemento contribuye a las causas de daño a la salud y muerte, y producen grandes costos en los servicios de salud.

2. Medio Ambiente: Incluye los asuntos externos al cuerpo humano como la contaminación del agua, el aire, la disposición de excretas y lo relacionado con el medio ambiente social.

3. Estilo de Vida: Incluye las decisiones tomadas por los individuos, que afectan su salud.
4. Servicios de Salud: En estos entran la calidad, cantidad, distribución, naturaleza y relaciones de los recursos y personas encargadas de prestar los servicios médicos.

A través del concepto de nivel de salud, se ha hecho la tentativa de cuantificar el estado de salud colectivo. En Caldas (como en el resto del país) no se cuenta con métodos de medida o indicadores óptimos para realizar dicha medición y la forma habitual de hacerlo, sigue siendo a través de tasas de morbimortalidade incapacidades (indicadores negativos).

Para acercarnos a la descripción del concepto de campo de salud teniendo en cuenta los vectores determinantes, sería útil examinar los indicadores del nivel de salud (tasas de morbimortalidad, 
índices de natalidad y letalidad, esperanza de vida al nacer) en relación con los indicadores de nivel de vida (económicos, sociales, culturales, demográficos y educativos) y los indicadores de actividades y servicios de salud (indicadores de servicios públicos, número de médicos por habitante, índice de cama por habitante, entre otros).

\section{Algunas características del estado de salud en Caldas.}

Para la descripción del estado de salud en Caldas, se utilizarán como indicadores las tasas de morbimortalidad y egresos hospitalarios por mil habitantes.

La población de Caldas presenta una distribución espacial del $61 \%$ en zona urbana y $39 \%$ en zona rural. La pirámide poblacional es de base ancha y una tercera parte de ella es menor de 14 años. En 1992 se observó cómo las enfermedades infecciosas del aparato respiratorio y digestivo, constituyeron las dos primeras causas de morbilidad observadas en la consulta médica en edades comprendidas entre menores de 1 año hasta 14 años. En este mismo grupo etáreo la desnutrición proteico-calórica aún sigue presentándose entre las primeras diez causas de morbilidad. De otrolado aparecen las laceraciones, heridas y traumatismos, ascendiendo a medida que aumenta la edad como consecuencia de accidentes caseros, accidentes automovilísticos y violencia, constituyéndose en la segunda causa de morbilidad en el grupo de 15 a 44 años. En este mismo grupo de edad se observan característicamente las enfermedades relacionadas con el embarazo siendoésta, laséptima causa de morbilidad. Es de resaltar que a partir de los 45 años se observa una mayor incidencia de enfermedades crónicas, destacándose la enfermedad hipertensiva como la segunda causa de morbilidad y en el grupo de 60 años y más se acentúa esta característica, convirtiéndose en la primera causa de morbilidad, seguida de otras enfermedades del aparato digestivo, artritis, enfermedades del corazón, entre otros.
Como causas de mortalidad en menores de 1 año se ven las afecciones hipóxicas del feto o del recién nacido o en el período prenatal ocupando el segundo lugar entre las diez primeras causas. En el grupo de 1 a 4 años las infecciones (enteritis y otras diarreas y neumonías) ocupan los dos primeros lugares de mortalidad. Ya en esta edad aparecen otros diagnósticos como neumoconiosis (tercer lugar), accidentes causados por sumersión, sofocación y cuerpos extraños y otros accidentes (cuarto y quinto lugar); la desnutrición proteicocalórica en el sexto lugar. Es de interés observar cómo los accidentes de automóviles y otros accidentes ocupan las dos primeras causas de mortalidad, seguidos de homicidios y lesiones infringidas intencionalmente en el grupo de 5 a 14 años.

Luego aparecen en lugares sucesivos la leucemia y los accidentes por sumersión, inmersión, sofocación y cuerpos extraños. En los grupos etáreos siguientes entre 15 y 59 años los homicidios fueron la primera causa de mortalidad, seguidos por enfemedades cerebrovasculares e isquémicas del corazón y progresivamente por las enfermedades tumorales. En el consolidado de todas las edades la primera causa son los homicidios (violencia) seguidos por enfermedades del corazón y circulación pulmonar, enfermedades cerebrovasculares e infarto de miocardio.

El presente análisis se basa en la información obtenida del Servicio de Salud de Caldas, en donde la recolección de los datos se ha hecho a través de la codificación de enfermedades mal definidase inespecíficas, en la población de estrato socioeconómico medio y bajo, usuarios normales de los servicios de salud del sector oficial, ya que no se posee estadística sistematizada del sector privado.

La intención del presente informe es determinar el peso relativo de algunos de los condicionantes de la salud, sin desconocer la importancia de los otros factores que participan con mayor o menor influencia en los resultados de enfermar o morir. 
En la región caldense, el proceso es variable para los diferentes grupos de edad al igual que las características socio-culturales; pero para fines de políticas gubernamentales y decisiones en cuanto a la inversión en salud, se hace necesario generalizar sobre la población.

Es así como las infecciones continúan siendo la primera causa de morbilidad en el grupo menor de un año, lo que podría interpretarse como el resultante de un medio ambiente hostil, conceptualizándolo como deficiencias en los servicios públicos: precarios servicios de alcantarillado, recolección de basuras, disposición de excretas, hacinamiento, entre otros. Por otro lado, los estilos de vida de las familias de la región caldense podrían ser otro factor coadyuvante en la aparición de este tipo de patologías.

Otro punto que merece ser resaltadoes la incidencia progresiva de los traumatismos, lesiones y muertes causadas por el aumento de la violencia social vigente en el entorno social, que aparece en el grupo de edades comprendidas entre 5 y 14 años, hasta convertirse en la primera causa de morbimortalidad, reflejo de la descomposición social y de hábitos como el alcoholismo, la drogadicción y la indisciplina ciudadana. Este mismo ambiente social se prodiga sobre los menores de edad y se traduce en el trato violento descrito como accidentes causados por sofocación, inmersión y cuerpos extraños.

La intervención del Estado en la atención de estas entidades se ha encaminado al diagnóstico precoz y tratamiento, sin tener en cuenta que la modificación de estos factores ambientales tendría una repercusión mayor y probablemente, un menor costo social y económico a corto plazo.
El ambiente hostil reinante opaca la posibilidad de desarrollar una mayor esperanza de vida por parte de las personas, con todo el significado social, familiar, económico que este representa. Ello, sin tener en cuenta que estos individuos no desarrollarán ninguna enfermedad de tipo crónico o de etiología biológica pura.

Entidades nosológicas como tumores malignos, leucemias y enfermedades degenerativas se presentan con mayor prevalencia en grupos de edades con una expectativa de vida menor, donde la violencia pierde su influjo. Este grupo de patologías en su tratamiento contextual tienen un enfoque eminentemente biologista, olvidando de paso las connotaciones sociales que representa para el enfermo y su entorno, para manejar una enfermedad crónica y por lo general letal.

Resaltamos que en el informe se escapan factores determinantes del proceso, que generalmente no son ponderables con los indicadores mencionados, como el estado subjetivo de bienestar, las condicionespsíquicas individuales, laaccesibilidad al tiempo de ocio y recreación, entre otros, que nos permitirían ver la salud desde un punto de vista positivo y desde una manera más integral y aproximada.

Finalmente, indicadores de necesidades insatisfechas de vivienda, servicios públicos, educación o de bienestar, nos permitirían hacer proyecciones y en general plantear políticas de salud en un concepto más dinámico y de acuerdo a las necesidades de la población, y no sólo a través de la evidencia de los problemas, sino involucrando aspectos como calidad de vida y en general, de salud. Desde esta perspectiva se abre el compromiso universitario e intersectorial para la solución de estos problemas. 